\title{
Tudo como dantes no quartel de Abrantes: eleições de 2016 em São José dos Pinhais
}

\author{
Ana Crhistina Vanali ${ }^{1}$
}

- Enviado em 15/09/2016

- Aprovado em 18/09/2016
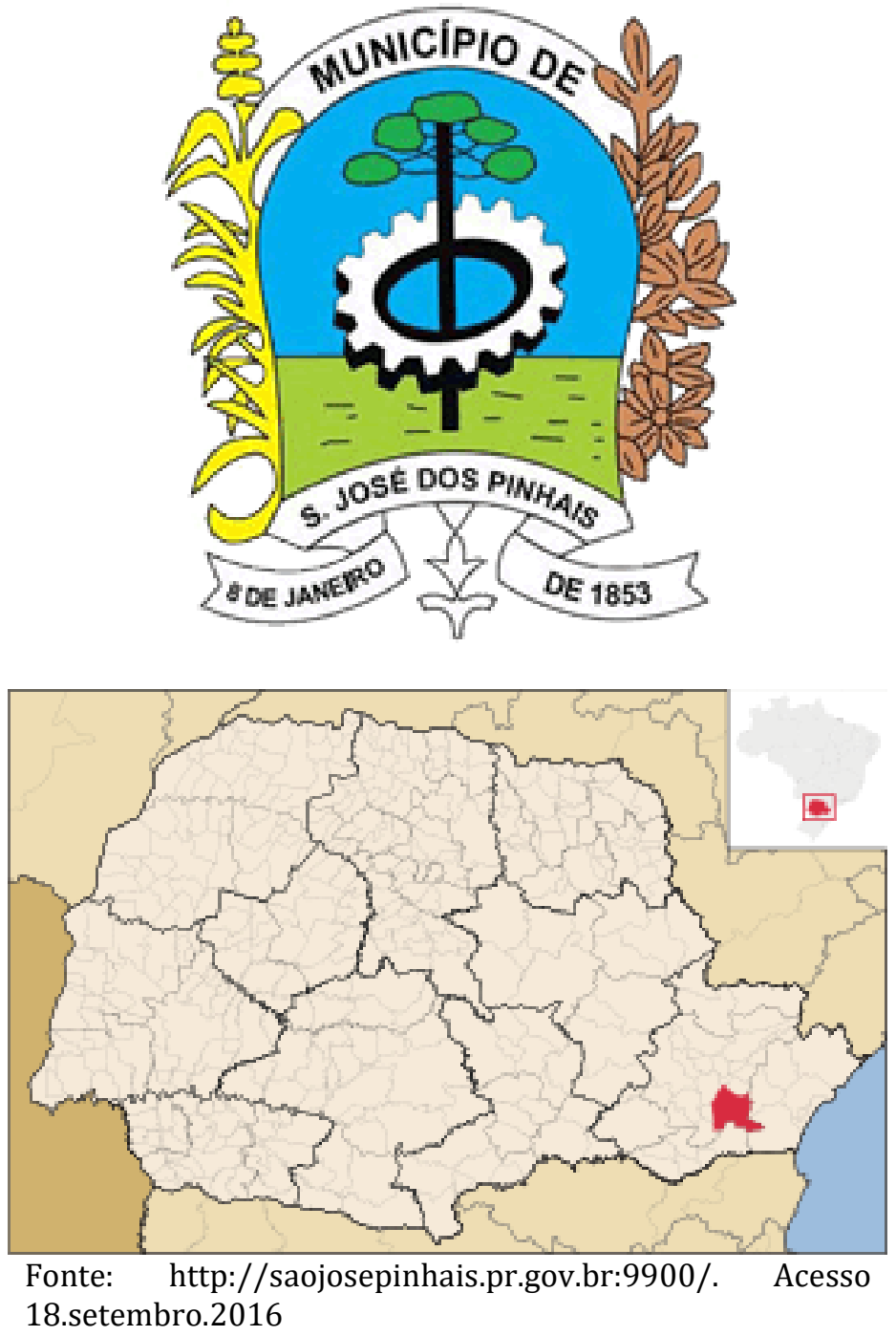

${ }^{1}$ Doutoranda em Sociologia pela UFPR. Endereço eletrônico: anacvanali@yahoo.com.br 


\title{
Tudo como dantes no quartel de Abrantes: eleições de 2016 em São José dos Pinhais
}

\author{
Ana Crhistina Vanali
}

São José dos Pinhais é um dos municípios da região metropolitana de Curitiba. Possui 292.934 habitantes ${ }^{2}$. De acordo com o Tribunal Superior Eleitoral, São José dos Pinhais é a 6 ${ }^{\mathbf{a}}$ cidade do Paraná com maior número de eleitores entre os 399 municípios $^{3}$ do Estado com 170.706 eleitores. ${ }^{4}$

A vila de São José dos Pinhais foi criado pela Lei no 10 de 16 de julho de 1852, da província de São Paulo, sendo que o estabelecimento político deu-se com a instalação da Câmara dos Vereadores em 8 de janeiro de 1853. Em 27 de dezembro de 1897, a vila foi elevada à categoria de cidade (MAROCHI, 2007) 5 .

São José dos Pinhais pode ser considerada uma cidade média, a segunda mais populosa da Região Metropolitana de Curitiba. Foi na cidade que o ex-presidente da república, Nereu Ramos, morreu em um acidente aéreo, na Colônia Murici no ano de 19586. É também a cidade onde nasceu Ana Paula Caldeira, o primeiro bebê-de-proveta do Brasil. É o terceiro polo

\footnotetext{
${ }^{2}$ Segundo http://cidades.ibge.gov.br/painel/painel.php?codmun=412550. Acesso 10.setembro.2016

${ }^{3}$ Fica atrás de Curitiba, Ponta Grossa, Maringá, Londrina e Cascavel, cidades com mais de 200 mil eleitores exigidos por lei para levar as eleições municipais ao segundo turno. No ano de 2016 foi realizado o cadastramento biométrico dos eleitores do município, mas não foi atingido o número mínimo necessário para o segundo turno e nas eleições de 2016 haverá apenas um turno na cidade. Disponível em http://giroemsaojosedospinhais.com.br/2016/03/14/sao-jose-dos-pinhais-pode-ter-segundo-turno-naseleicoes-2016/. Acesso 10. Setembro.2016
}

4 Disponível em http://www.tre-pr.jus.br/eleitor/zonas-eleitorais/zonas-eleitorais-tre-pr-pesquisa-pormunicipio-1. Acesso 10.setembro.2016.

${ }^{5}$ MACROCHI, Maria Angelica (2007). De freguesia a diocese: a trajetória da igreja católica em São José dos Pinhais (1690-2007). Curitiba: Travessa dos Editores.

6 Disponível em Acidente que matou Jorge Lacerda e Nereu Ramos mudou rumo da política em Santa Catarina. http://dc.clicrbs.com.br/sc/noticias/noticia/2014/06/acidente-que-matou-jorge-lacerda-e-nereuramos-mudou-rumo-da-politica-em-santa-catarina-4526220.html. Acesso 10.setembro.2016. 
automotivo do Brasil, abrigando montadoras da Volkswagen, Audi, Nissan e Renault. É sede do Aeroporto Internacional Afonso Pena, principal terminal aéreo do Paraná.

O atual prefeito da cidade é Luiz Carlos Setim (DEM), que não vai concorrer à reeleição, e apoia a coligação São José Melhor que tem como candidato a prefeito seu atual vice, Toninho da Farmácia.

0 ex-presidente da FIEP, Rodrigo Rocha Loures, era um dos fortes pré-candidatos à Prefeitura de São José dos Pinhais nas eleições municipais deste ano. Mas em junho sua desistência foi anunciada por seu filho, o ex-deputado federal e atual chefe de Relações Institucionais da Presidência da República, Rodrigo Santos Rocha Loures, ao garantir que o pai assumiria a direção geral da Itaipu Binacional, indicado pelo presidente Michel Temer (PMDB) ${ }^{7}$. A notícia da desistência de Rocha Loures foi anunciada na edição online do Jornal Gazeta do Povo do dia 3 de junho de 2016. Ao anunciar a desistência, Rocha Loures indicou o nome do também empresário são-joseense, Elói Bastos. Tal indicação foi considerada pelos filiados do partido como uma imposição feita por Rocha Loures e isso não pegou bem nos bastidores do PMDB. Rocha Loures era considerado um adversário forte para os demais concorrentes.

Eloí Bastos, devido à falta de unanimidade no apoio ao seu nome, também desistiu da candidatura à prefeitura e o PMDB de São José dos Pinhais em convenção realizada dia 31 de julho ${ }^{8}$ decidiu pelo apoio à chapa "São José Melhor", encabeçada por Toninho da Farmácia, do PSC.

São três os candidatos nas eleições de 2016 à prefeitura de São José dos Pinhais são os seguintes:

\section{TONINHO DA FARMÁCIA}

Vice: Thiago Bührer

\footnotetext{
7 Disponível em http://www.gazetadopovo.com.br/vida-publica/rodrigo-rocha-loures-sera-o-diretor-geral-de-itaipu6512 fiwbvwdyoerm2wrylict8. Acesso 10.setembro.2016.

8 Disponível em http://pmdbsjp.com.br/2016/08/pmdbsjp-fara-coligacao-para-eleicao-majoritaria-2016/. Acesso 10.setembro.2016.
} 
Coligação SÃO JOSÉ MELHOR - PP / PSB / PSDB / PSDC / PMN / PSC / PSD / PMDB / PPS / PRB / PRTB / PRP / PT do B / PTC / DEM

Toninho da Farmácia é o vice do atual prefeito Luiz Carlos Setim (gestão 2013-2016). Conta com o apoio de Ratinho Junior (PSD), Secretário de Estado de Desenvolvimento Urbano do Paraná, do deputado federal pelo Paraná Leopoldo Meyer (PSB) e do deputado estadual Francisco Bührer (pai de seu vice-candidato).

Toninho reside em São José dos Pinhais há mais de 30 anos, É proprietário de uma rede farmacêutica. Iniciou a vida pública como vereador no ano de 1997. Foi reeleito vereador para a legislatura seguinte, de 2001 a 2004. Depois foi vice-prefeito da gestão de Leopoldo Meyer 2005-2008. Em 2008 é eleito novamente vereador na legislatura de 2009 a 2012. É viceprefeito da atual gestão de Luiz Carlos Setim (2013-2016) (MAROCHI, 2003) ${ }^{9}$. Foi candidato a deputado estadual nas eleições de 2014, obtendo 22.929 votos. Não foi eleito, mas assumiu como suplente em 2014. Declarou não ter nenhum parente na política. ${ }^{10}$

O vice Thiago Bürher, é ex-secretário de Esporte e Lazer de São José dos Pinhais (da atual gestão) e foi cotado como principal nome para substituir o atual prefeito. Thiago é presidente do PSDB de São José dos Pinhais e desistiu da pré-candidatura a prefeito para anunciar as bancadas do PSDB e PP que seria candidato a vice-prefeito de Toninho da Farmácia, na chapa da situação, tudo isso após muitas reuniões com o deputado federal Leopoldo Meyer, deputado estadual Francisco Bührer e o Prefeito Setim, que indicaram e apoiaram esta união. É a primeira eleição em que se candidata.

Thiago é filho de José Francisco Bührer que foi vereador de São José dos Pinhais por duas legislaturas, de 1989 a 1996, presidente da Câmara Municipal em 1995 e 1996. Foi viceprefeito de 1997, período em que ainda exerceu o cargo de secretário municipal de articulação com a comunidade. Em 2000 foi reeleito vice-governador. Foi eleito deputado estadual pela primeira vez em 2002, sendo reeleito nas legislaturas seguintes até a atual.

\footnotetext{
${ }^{9}$ MACROCHI, Maria Angelica (2003). Câmara Municipal de São José dos Pinhais: 150 anos (1853-2003). SJP: CMSJP.

10 Disponível em http://www.gazetadopovo.com.br/vida-publica/eleicoes/2014/candibook//candidato/antoninobenedito-fenelon-toninho-da-farmacia-psc-20020/. Acesso 10.setembro.2014.
} 
Thiago é trineto de Benjamin Claudino Ferreira, prefeito de São José dos Pinhais entre 1924 e 1932. Seu tio-avô Francisco Ari Claudino foi o primeiro prefeito eleito de Mandirituba. ${ }^{11}$

\section{Coligação SÃO JOSÉ MELHOR}
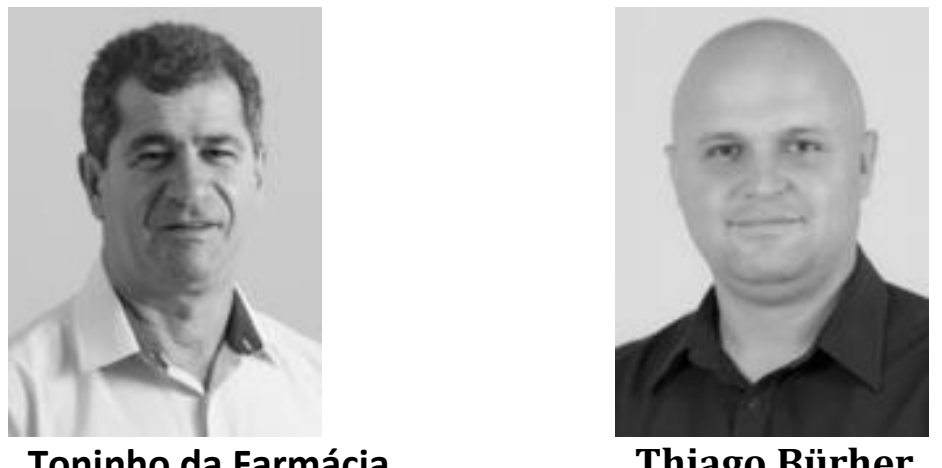

Toninho da Farmácia

Thiago Bürher

Fonte: https://www.eleicoes2016.com.br/. Acesso 10.setembro.2016

\section{SYLVIO MONTEIRO}

Vice: Lucia Stocco

Coligação Renovação com Responsabilidade - PTB / PC do B / PV / PROS / PR / PEN / PHS

Sylvio Monteiro (PTB), presidente da Câmara de Vereadores, concorre à prefeitura com o apoio do deputado estadual Nelson Justus (DEM), que apesar de estar sendo acusado de corrupção, é seu padrinho e principal patrocinador da campanha12. Foi eleito pela primeira

11 Disponível em http://www.gabinetevirtual.com.br/franciscobuhrer/site/conteudo.asp?cad=200000\&cod=732043. Acesso 10.setembro.2014.

${ }^{12}$ Ver reportagem "Aliado colocou 20 parentes na AL: Justus admite que sabia da rede de familiares do chefe de gabinete e disse achar isso "perfeitamente normal"”. Gazeta do Povo de 06.04.2010. Na série Diários Secretos da ALEP aparece o infográfico do Clã dos Monteiros demonstrando como pelo menos 20 membros dessa família estavam nomeadas com cargo de comissão ligadas na época da presidência da ALEP do deputado Nelson Justus e do chefe de gabinete Sergio Monteiro, pai do candidato Sylvio Monteiro. Sua mãe, a professora Lourdes Monteiro também aparece 
vez, em 2004 como o vereador mais jovem do estado do Paraná, sendo reeleito em 2008. Está no terceiro mandato como vereador e é o atual presidente da Câmara Municipal. Recebe muitas críticas como presidente da CMSJP, entre elas a resistência em não exonerar os 126 cargos em comissão que o Ministério Público apontou como inconstitucionais. ${ }^{13}$ Sylvio Monteiro é filho de Sergio Monteiro, o ícone dos Diários Secretos da ALEP. ${ }^{14}$

A vice, Lúcia Stocco foi eleita vereadora em 2008, sendo reeleita em 2012. Foi candidata a deputada estadual nas eleições de 2014, obteve 9524 votos e não foi eleita.

\section{Coligação Renovação com Responsabilidade}

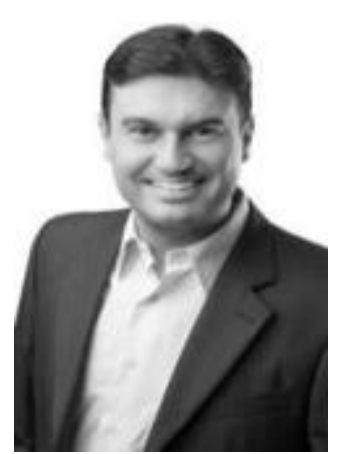

Sylvio Monteiro

Fonte: https://www.eleicoes2016.com.br/. Acesso 10.setembro.2016

\section{MAURO KNORST}

Vice: Pedro Scherer

Coligação UNIDOS POR SÃO JOSÉ - PTN / REDE / PPL

na relação e na época da reportagem, em 2010, foi encontrada trabalhando no gabinete do filho Sylvio que era vereador em São José dos Pinhais quando na verdade deveria estar atuando na ALEP.

14 Ver TABATCHEIK, Gabriel. DESVENDANDO OS DIÁRIOS SECRETOS: UMA ANÁLISE DO USO DOS CARGOS EM COMISSÃO DA ASSEMBLEIA LEGISLATIVA DO PARANÁ (2006-2010). IN: REVISTA NEP (Núcleo de Estudos Paranaenses) Curitiba, v.1, n.1, p. 179-202, dezembro 2015 
Não foram encontrados dados sobre a trajetória política de Mauro Knorst pois ele não concorreu a cargos públicos e não foi eleito nos últimos anos.

0 vice, Pedro Scherer é liderança comunitário tendo liderado a criação criado da Federação Municipal das Associações de Moradores. Tem forte envolvimento com a comunidade religiosa do município liderando várias pastorais.

\section{Coligação Unidos por São José}

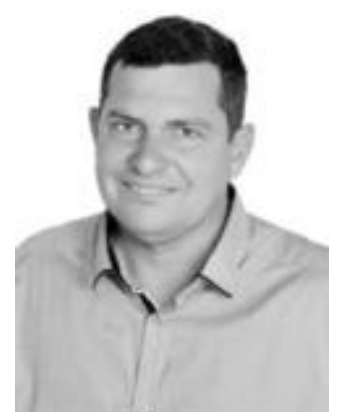

Mauro Kornst

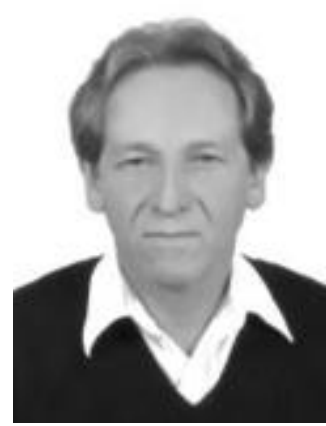

Pedro Scherer

Fonte: https://www.eleicoes2016.com.br/. Acesso 10.setembro.2016 
QUADRO COM OS CANDIDATOS A PREFEITO E VICE-PREFEITO DE SÃO JOSÉ DOS PINHAIS

ELEIÇÕES DE 2016

\begin{tabular}{|c|c|c|c|c|c|c|c|}
\hline NOME & IDADE & $\begin{array}{c}\text { NATURALI } \\
\text { DADE }\end{array}$ & $\begin{array}{c}\text { ESTADO } \\
\text { CIVIL }\end{array}$ & OCUPAÇÃO & $\begin{array}{c}\text { GRAU DE } \\
\text { INSTRUÇÃo }\end{array}$ & PARTIDO & Cargo \\
\hline $\begin{array}{l}\text { Toninho da } \\
\text { Farmácia } \\
\text { (Antonio } \\
\text { Benedito } \\
\text { Fenelon) }\end{array}$ & $\begin{array}{c}54 \text { anos } \\
(23 / 04 / \\
1962)\end{array}$ & $\begin{array}{c}\text { Umuarama- } \\
\text { PR }\end{array}$ & casado & comerciante & $\begin{array}{c}\text { Ensino } \\
\text { fundamental } \\
\text { completo }\end{array}$ & $\begin{array}{c}\text { PSC } \\
\text { (Partido } \\
\text { Social } \\
\text { Cristão) }\end{array}$ & $\begin{array}{c}\text { Prefeito } \\
\text { Coligação São } \\
\text { José Melhor }\end{array}$ \\
\hline $\begin{array}{l}\text { Thiago } \\
\text { Fernando } \\
\text { Bührer }\end{array}$ & $\begin{array}{c}32 \text { anos } \\
(26 / 11 / \\
1983)\end{array}$ & $\begin{array}{l}\text { São José dos } \\
\text { Pinhais - PR }\end{array}$ & casado & $\begin{array}{c}\text { Fisioterapeut } \\
\text { a e terapeuta } \\
\text { ocupacional }\end{array}$ & $\begin{array}{c}\text { Superior } \\
\text { Completo }\end{array}$ & $\begin{array}{c}\text { PSDB } \\
\text { (Partido da } \\
\text { Social } \\
\text { Democracia } \\
\text { Brasileira) }\end{array}$ & $\begin{array}{l}\text { Vice-prefeito } \\
\text { Coligação São } \\
\text { José Melhor }\end{array}$ \\
\hline $\begin{array}{l}\text { Sylvio } \\
\text { Monteiro } \\
\text { Neto }\end{array}$ & $\begin{array}{c}31 \text { anos } \\
(17 / 05 / \\
1985)\end{array}$ & $\begin{array}{c}\text { Curitiba - } \\
\text { PR }\end{array}$ & solteiro & empresário & $\begin{array}{l}\text { Superior } \\
\text { Completo }\end{array}$ & $\begin{array}{c}\text { PTB } \\
\text { (Partido } \\
\text { Trabalhista } \\
\text { Brasileiro) }\end{array}$ & $\begin{array}{c}\text { Prefeito } \\
\text { Coligação } \\
\text { Renovação } \\
\text { com } \\
\text { Responsabili } \\
\text { dade }\end{array}$ \\
\hline $\begin{array}{l}\text { Mari Lucia } \\
\text { Stoco Ulson }\end{array}$ & $\begin{array}{c}58 \text { anos } \\
(26.11 .1 \\
957)\end{array}$ & $\begin{array}{c}\text { São José dos } \\
\text { Pinhais - } \\
\text { PR }\end{array}$ & casada & pedagoga & $\begin{array}{c}\text { Superior } \\
\text { Completo }\end{array}$ & $\begin{array}{c}\text { PEN } \\
\text { (Partido } \\
\text { Ecológico } \\
\text { Nacional) }\end{array}$ & $\begin{array}{c}\text { Vice- Prefeita } \\
\text { Coligação } \\
\text { Renovação } \\
\text { com } \\
\text { Responsabili } \\
\text { dade }\end{array}$ \\
\hline $\begin{array}{l}\text { Mauro } \\
\text { Antonio } \\
\text { Knorst }\end{array}$ & $\begin{array}{c}42 \text { anos } \\
(09 / 06 / \\
1974)\end{array}$ & $\begin{array}{l}\text { Marechal } \\
\text { Cândido } \\
\text { Rondon - } \\
\text { PR }\end{array}$ & casado & empresário & $\begin{array}{c}\text { Ensino médio } \\
\text { completo }\end{array}$ & $\begin{array}{c}\text { REDE } \\
\text { (Rede } \\
\text { Sustentabili } \\
\text { dade) }\end{array}$ & $\begin{array}{l}\text { Prefeito } \\
\text { Coligação } \\
\text { Unidos por } \\
\text { São José }\end{array}$ \\
\hline $\begin{array}{l}\text { Pedro } \\
\text { Scherer }\end{array}$ & $\begin{array}{c}64 \text { anos } \\
(18.08 .1 \\
952)\end{array}$ & $\begin{array}{l}\text { São Pedro } \\
\text { de } \\
\text { Alcântara - } \\
\text { SC }\end{array}$ & casado & $\begin{array}{c}\text { Servidos } \\
\text { público civil } \\
\text { aposentado }\end{array}$ & $\begin{array}{l}\text { Ensino médio } \\
\text { completo }\end{array}$ & $\begin{array}{c}\text { PTN } \\
\text { (Partido } \\
\text { Trabalhista } \\
\text { Nacional) }\end{array}$ & $\begin{array}{l}\text { Vice -Prefeito } \\
\text { Coligação } \\
\text { Unidos por } \\
\text { São José }\end{array}$ \\
\hline
\end{tabular}

Elaboração da autora 


\section{Considerações finais}

Apesar de uma figura de fora do campo político tradicional como o candidato Mauro figurar entre os candidatos, as pesquisas indicam que não teremos mudança de linha política na prefeitura de São José dos Pinhais e tudo permanecerá com a mesma classe política no poder. Há 16 anos o município encontra-se no comando da mesma linhagem política indicada por Luiz Carlos Setim que após dois mandatos no executivo municipal deixou seu sucessor. Depois na retomada da prefeitura decidiu não concorrer à eleição, mas pelo visto deixará seu sucessor novamente no comando. Ou seja, tudo como dantes no quartel de Abrantes! 


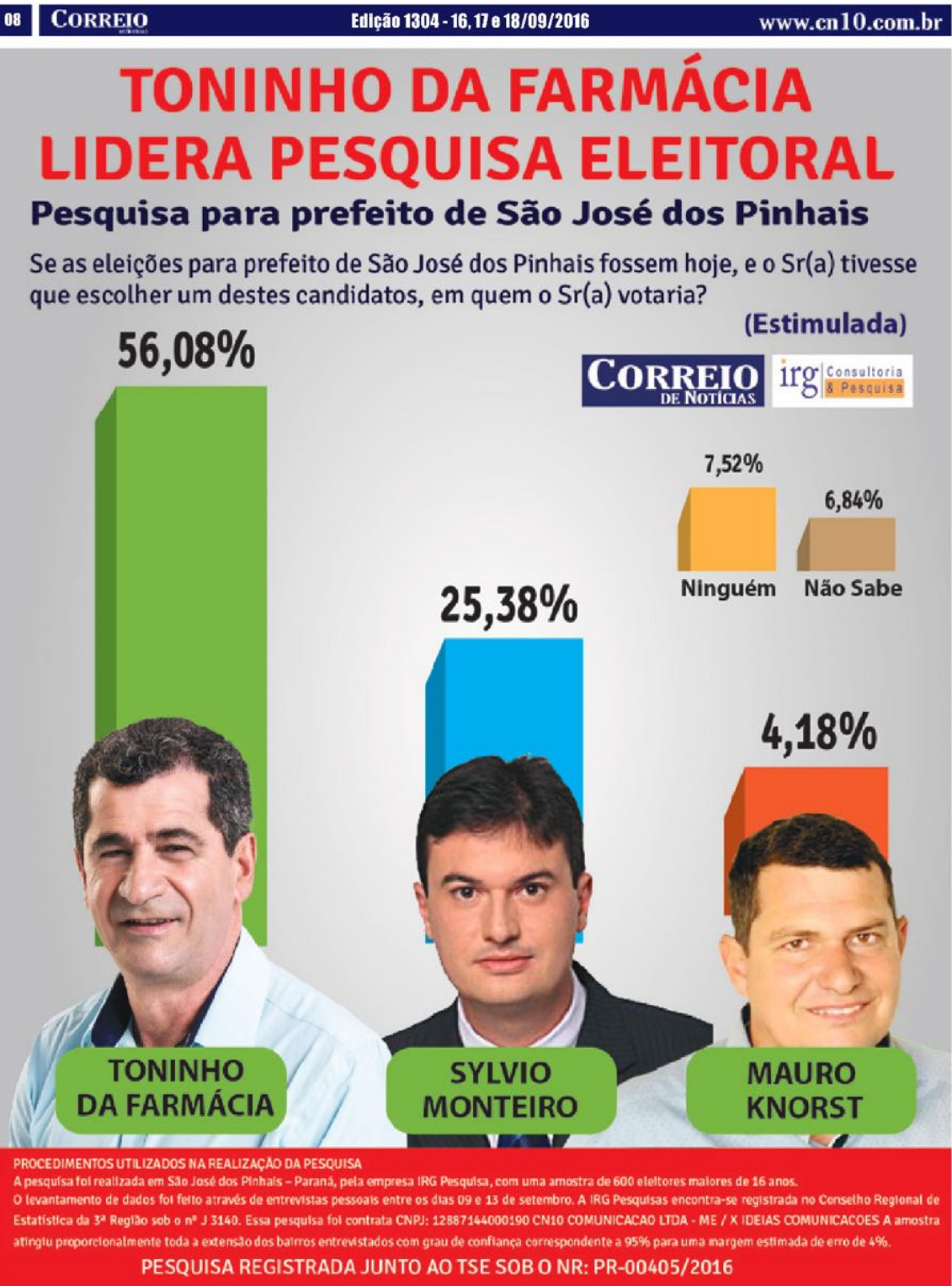

Fonte: http://www.sipnews.com/2016/09/nova-pesquisa-eleitoral-em-sao-jose-dos.html 